\title{
Estruturação de um programa de qualificação em gestão da qualidade, segurança e saúde ocupacional: apresentação dos resultados de uma aplicação piloto realizada no aglomerado metal-mecânico de Sertãozinho - São Paulo
}

\author{
Structuring a qualification program on quality, occupational health and \\ safety management: presenting the results of a pilot application in the \\ metal-mechanic cluster in Sertõzinho, São Paulo state, Brazil
}

\author{
Gislaine Aparecida Vitoreli ${ }^{1}$ \\ Luiz Cesar R. Carpinetti' \\ Mateus Cecílio Gerolamo' \\ Juliano Endrigo Sordan'1 \\ Carlos Henrique Bertucci Lima ${ }^{1}$
}

\begin{abstract}
Resumo: Este artigo apresenta e discute a estruturação de um programa de qualificação para pequenas e médias empresas em gestão de qualidade, segurança e saúde ocupacional. O programa de qualificação proposto inclui a estruturação de um modelo de sistema de gestão integrado bem como a estruturação dos processos de implementação e auditoria deste sistema. O método de pesquisa-ação foi adotado para a condução da aplicação piloto desta proposta que foi realizada no aglomerado metal-mecânico de Sertãozinho, São Paulo. Os resultados preliminares da aplicação piloto apontam para possibilidade de operacionalização da proposta que pode contribuir em dois aspectos importantes: maior competitividade para as empresas do aglomerado e melhoria na competência da governança local em coordenar ações conjuntas. Ressalta-se ainda a existência de desafios para a continuidade do programa de qualificação, sendo a sua manutenção pela agência de coordenação local um dos mais críticos.
\end{abstract}

Palavras-chave: Aglomerados industriais. Pequenas e médias empresas. ISO 9001. Segurança e saúde ocupacional. OHSAS 18001. Gestão da qualidade.

\begin{abstract}
This article aims to present and discuss the framework of a qualification program on quality, occupational health and safety management for small and medium sized enterprises. The proposed qualification program includes an integrated management system model, as well as a process for conducting periodic audits. Action research was the methodological approach chosen to conduct the pilot application of the proposed qualification program. The pilot application was performed with a group of small and medium enterprises of the Sertãozinho's metal-mechanic cluster, located in the state of São Paulo Preliminary results indicate the possibility of operationalization of the proposal as well as its contributions to two key aspects: increase competitiveness of the companies in the cluster and increase competence of the cluster governance team to coordinate joint actions. Nevertheless, there are great challenges to maintain the qualification program, and its maintenance is one of the most critical challenges faced by the governance team.
\end{abstract}

Keywords: Industrial clusters. Small and medium enterprises. ISO 9001. Occupational health and safety. OHSAS 18001. Quality management.

\footnotetext{
${ }^{1}$ Departamento de Engenharia de Produção, Escola de Engenharia de São Carlos - EESC, Universidade de São Paulo - USP, Av. Trabalhador São-carlense, 400, CEP 13566-590, São Carlos, SP, Brasil, e-mail: gislaineavitoreli@gmail.com; carpinet@sc.usp.br; gerolamo@sc.usp.br; julianosordan@yahoo.com.br; carlos.bertucci@gmail.com
} 


\section{Introdução}

A adoção de diversos sistemas de gestão pelas organizações tem sido cada vez mais frequente, o que pode ser atribuído a diversos fatores como a necessidade de melhorar as suas relações com os stakeholders, reduzir não conformidades e atender às demandas do mercado (ZUTSHI; SOHAL, 2005).

Vários trabalhos mostram os impactos positivos da implementação de sistemas de gestão como a ISO 9001 (GOTZAMANI et al., 2007; SINGH; FENG; SMITH, 2006; YEUNG; MOK, 2005). Outros relatam a melhoria do desempenho que pode ser alcançada com a implementação de sistemas de gestão de segurança e saúde ocupacional (MUÑIZ; PÉON; ORDÁZ, 2009; BOTTANI; MONICA; VIGNALI, 2009).

A crescente adoção de sistemas de gestão pelas organizações pode ser evidenciada pelos números apresentados por uma pesquisa realizada pela Organização Internacional de Normalização (INTERNATIONAL..., 2008a), que mostra que até o final de 2007 existiam mais de 900.000 empresas certificadas ISO 9001 e 150.000 certificadas ISO 14001. O crescimento mundial no número de certificações ISO 9001 e ISO 14001, entre os anos de 2003 e 2007, pode ser verificado por meio da Figura 1.

Assim, com as organizações adotando cada vez mais sistemas de gestão normalizados, seja devido aos benefícios que estes podem proporcionar ou devido às exigências de stakeholders, a integração tem sido vista como uma maneira efetiva de alinhar e integrar os requisitos desses sistemas. Esta integração pode trazer diversos benefícios, além de gerar maior eficiência em diversos aspectos, amenizando possíveis dificuldades de gerenciamento e reduzindo custos (WILKINSON; DALE, 1999; ZUTSHI; SOHAL, 2005; JORGENSEN; REMMEN; MELLADO, 2006). Modelos para a integração dos sistemas de gestão são apresentados em alguns trabalhos como os de Zeng, Shi e Lou (2007) e Jonker e Karapetrovic (2004).
A integração de sistemas de gestão também tem se tornado uma questão importante para as pequenas empresas. Apesar das diversas abordagens para a integração de sistemas de gestão não serem influenciadas pelo tamanho das organizações, pequenas empresas podem ter dificuldades na sua implementação. Esta dificuldade pode ser verificada até mesmo com a implementação de um único sistema de gestão, conforme observado em um estudo de caso realizado por Aggelogiannopoulos, Drosinos e Athanasopoulos (2007) sobre a implementação de um sistema de gestão da qualidade. Alguns dos obstáculos observados foram falta de recursos humanos, falta de recursos financeiros e falta de conhecimento e experiência com a norma.

Desta forma, esta questão se torna um tema em que a colaboração, ações conjuntas e compartilhamento de conhecimento entre empresas de um aglomerado ou rede de empresas pode se tornar altamente vantajoso.

Aglomerados industriais vêm recebendo atenção crescente de pesquisadores, órgãos governamentais e profissionais, em geral devido à vantagem competitiva e desenvolvimento regional que possibilitam (PORTER, 1998; MYTELKA; FARINELLI, 2000; SÖLVELL; LINDQUIST; KETELS, 2003). Estudos afirmam que clusters industriais são essenciais para o desenvolvimento econômico de uma região ou até mesmo de um país (PORTER, 1998; KRUGMAN, 1998; SCHMITZ, 1999). Aglomerados industriais são concentrações geográficas de empresas interconectadas, fornecedores especializados, provedores de serviços, firmas em indústrias relacionadas e instituições associadas (e.g. universidades, associações comerciais) em um campo particular em que estas organizações competem, mas também cooperam (PORTER, 1998).

Vantagens como trabalhadores especializados e fácil acesso a fornecedores (economias externas) podem contribuir para a redução de custos nas empresas pertencentes a um aglomerado (SCHMITZ; NADVI, 1999). No Brasil, um estudo identificou 193 aglomerados

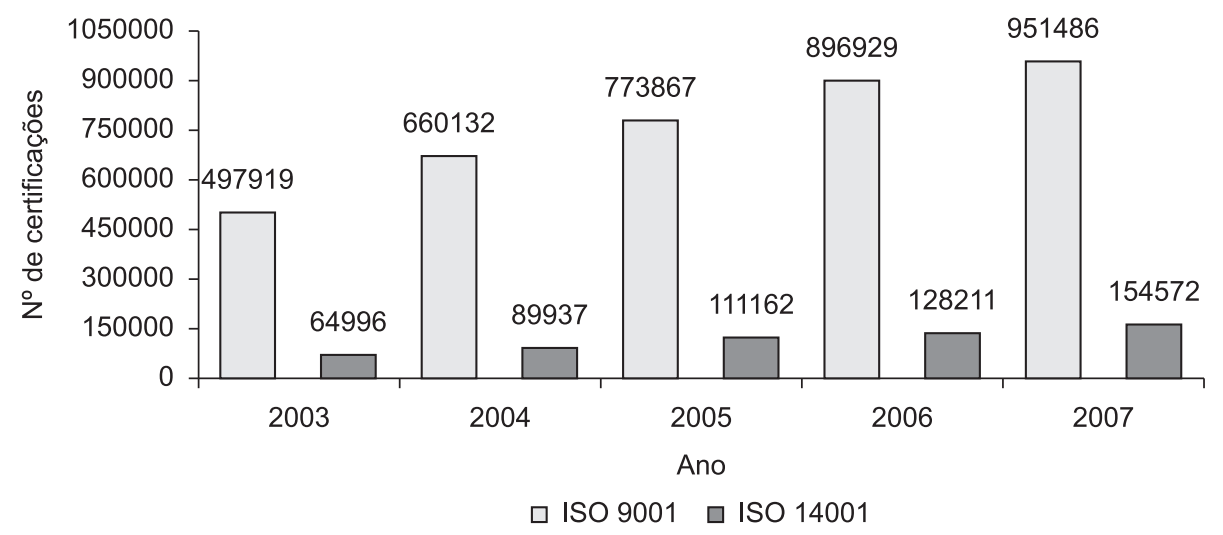

Figura 1. Certificações ISO 9001 e ISO 14001 no mundo. Fonte: International Organization for Standardization (2008a). 
industriais compostos por 77 mil firmas, sendo grande parte delas pequenas, as quais empregavam cerca de 680 mil pessoas (PUGA, 2003). No Brasil, empresas com até 99 empregados correspondem a 99,3\% do número total de empresas (Instituto Brasileiro de Geografia e Estatística, 2008).

Empresas localizadas em aglomerados, principalmente pequenas e médias empresas, podem se beneficiar de economias externas, colaboração e compartilhamento de conhecimento (UNITED..., 2001; KARAEV, 2007; CAPÓ-VICEDO; EXPÓSITOLANGA; MOLINA-MORALES, 2008; WOLFE; NELLES, 2008). Devido às vantagens que os aglomerados podem trazer, tanto para as empresas como para o desenvolvimento regional, várias políticas públicas vêm sendo desenvolvidas, como, por exemplo, a experiência da Indonésia relatada por Tambunan (2005). No Brasil, também existem diversas iniciativas (AMATO-NETO, 2009). Pode-se citar também as iniciativas desenvolvidas pelo SEBRAE (Serviço Brasileiro de Apoio às Pequenas e Micro Empresas), para dar suporte às micro e pequenas empresas na melhoria organizacional e estimulo a ações conjuntas em aglomerados. Dado este contexto, verifica-se que uma forma de colaboração que pode ser benéfica para empresas de um aglomerado, especialmente pequenas empresas, é a implementação conjunta de sistemas de gestão. Contudo, esse tipo de ação necessita de coordenação de forma que seja viabilizada (SCHMITZ; NADVI, 1999; SÖLVELL; LINDQUIST; KETELS, 2003). Um facilitador é requerido para estimular empresas e instituições locais a colaborarem por um bem comum (BITITCI et al., 2004). Neste artigo, o termo coordenador ou agência de coordenação referem-se a este facilitador.

Assim, este trabalho apresenta uma proposta de um programa de qualificação, que deve ser implementada pela agência de coordenação de um cluster, a qual tem como papel viabilizar a implementação do sistema de gestão integrado de qualidade, segurança e saúde ocupacional, o que deve ser feito por meio do incentivo e viabilização da cooperação entre as empresas. O programa de qualificação proposto inclui um modelo de sistema de gestão integrado e um processo de implementação e auditoria.

Esta proposta foi testada em uma aplicação piloto que contou com a participação de pequenas e médias empresas do aglomerado metal-mecânico de Sertãozinho, localizado no Estado de São Paulo. O desenvolvimento desta aplicação piloto também contou com a contribuição de uma agência de coordenação local, o Centro Nacional das Indústrias do Setor Sucroenergético e Biocombustíveis (CEISE).

O CEISE é uma instituição que foi criada com o objetivo de representar o parque industrial da região de Sertãozinho e, atualmente, reúne as empresas do setor e as auxilia em vários aspectos, como inserção no mercado internacional e qualificação em atividades de gestão. O CEISE também oferece às empresas associadas serviços como assessoria jurídica, posto de atendimento do SEBRAE - Serviço Brasileiro de Apoio às Micro e Pequenas Empresas, realização de eventos (como feiras para a promoção dos produtos produzidos no aglomerado), dentre outros (CENTRO..., 2012).

O método de pesquisa adotado para a condução deste trabalho é a pesquisa-ação, o qual é discutido na seção 4. Uma revisão bibliográfica sobre os temas sistema de gestão da qualidade, segurança e saúde ocupacional, sistema de gestão integrado e aglomerados industriais é apresentada respectivamente nas seções 2 e 3 . A seção 5 apresenta a descrição detalhada da proposta, enquanto a seção 6 apresenta e discute a sua aplicação piloto no aglomerado metal-mecânico de Sertãozinho. Por fim, as considerações finais sobre o programa de qualificação e os resultados da aplicação piloto são apresentados na seção 7 .

\section{Sistemas de gestão}

\subsection{Considerações sobre as normas ISO 9001 e OHSAS 18001}

A ISO 9001 (INTERNATIONAL..., 2008b) é uma norma internacional de sistema de gestão da qualidade que tem como principal objetivo prevenir que a empresa entregue produtos que não atendam aos requisitos dos clientes. A partir da sua revisão no ano de 2000, os seus requisitos de gestão passaram a focar outros aspectos além das atividades de realização do produto, como a gestão de recursos humanos, comprometimento da alta direção e melhoria contínua, detalhados a seguir:

- Gerenciamento de recursos, principalmente recursos humanos, essenciais para garantir o atendimento dos requisitos do cliente durante o processo de realização do produto;

- Comprometimento da alta direção com o desenvolvimento, implementação e melhoria contínua do sistema de gestão da qualidade; e

- Melhoria da eficácia do sistema de gestão da qualidade, por meio da realização de auditorias, análise crítica do produto pela alta direção, pesquisas de satisfação dos clientes e planejamento e implementação de ações de melhoria.

Geralmente, os motivos para a implementação da norma ISO 9001 são classificados pela literatura em dois tipos: internos e externos. No trabalho de Prajogo (2011), são examinados o papel estratégico e o efeito desses dois tipos de motivos na implementação da ISO 9001. Os resultados mostraram que os motivos 
internos são orientados para melhor desempenho da empresa e impactam positivamente o processo de implementação quando comparados ao impacto gerado pelos motivos externos. Por fim, foi verificado que, quando a ISO é implementada por motivos internos, ocorre uma relação positiva entre o processo de implementação e a melhoria do desempenho da organização, enquanto os motivos externos produziram um efeito oposto.

A implementação de um sistema de gestão da qualidade não contribui somente para o atendimento das necessidades dos clientes, mas também auxilia na prevenção de custos de retrabalho, desperdícios e outras fontes de ineficiências (KOC, 2007; SINGH, 2008). Um estudo empírico conduzido por Briscoe, Fawcett e Todd (2005), o qual envolveu pequenas empresas canadenses e americanas, concluiu que pequenas empresas podem implementar a certificação ISO 9001 e ganhar competitividade se estas estabelecerem uma cultura de qualidade e fizerem com que as práticas façam parte da rotina da empresa.

A ampla aplicação e evolução dos sistemas de gestão da qualidade levaram ao desenvolvimento de outros sistemas de gestão, como é o caso da série de normas de avaliação de segurança e saúde ocupacional OHSAS 18001 (OCCUPATIONAL..., 2007). Esta norma apresenta requisitos para um sistema de gestão da segurança e saúde ocupacional e tem como principal objetivo permitir que as empresas previnam acidentes de trabalho e danos à saúde. Assim, os principais requisitos da norma referem-se ao estabelecimento, implementação e manutenção de procedimentos para identificação de perigos, avaliação de riscos e determinação de controles. Apesar das diferenças da estrutura dos requisitos das normas ISO 9001 e OHSAS 18001 (a estrutura da OHSAS 18001 é baseado no ciclo PDCA - Plan-Do-Check-Act), elas apresentam requisitos correspondentes, os quais são apresentados no Anexo A do documento que apresenta a norma OHSAS 18001 (OCCUPATIONAL..., 2007).

Em uma pesquisa realizada com 131 empresas, Muñiz, Péon e Ordáz (2012) identifica, entre outros aspectos, as razões para as empresas implementarem a OHSAS 18001. As principais razões apontadas pelas empresas como muito importantes para a implementação da OHSAS 18001 foram: prevenir acidentes e incidentes, melhorar o bem-estar dos trabalhadores no ambiente de trabalho, integrar a segurança na estratégia corporativa e para manter um comportamento socialmente responsável.

Outras pesquisas mostram o efeito da implementação da OHSAS nas organizações, entre elas está o trabalho de Bottani, Monica e Vignali (2009), que teve como objetivo avaliar as diferenças estatísticas de desempenho entre empresas que adotam e empresas que não adotam um sistema de gestão de SSO. Como resultados de uma investigação empírica em 116 empresas italianas do setor de manufatura, os autores observaram que, entre as empresas que adotavam um sistema de gestão de SSO, a maioria eram grandes empresas e grande parte delas percebe seu nível de desempenho em relação aos seus concorrentes como melhor ou extremamente melhor.

Em outro trabalho, Muñiz, Péon e Ordáz (2009) identificam e analisam o efeito das práticas de gestão de SSO num conjunto de indicadores de desempenho organizacional (agrupados em três dimensões: desempenho na segurança, desempenho da competitividade e desempenho econômico financeiro) por meio de um estudo empírico em empresas espanholas dos setores industrial, de serviços e de construção civil. Partindo das hipóteses de que o sistema de gestão de SSO têm impacto positivo nas três dimensões de desempenho citadas, os autores observaram que o sistema de gestão de SSO tem efeito mais forte no desempenho da competitividade, seguido do desempenho na segurança e, por último, um efeito positivo, mas menor, no desempenho econômico-financeiro. Diversos estudos mostram ainda a viabilidade da implementação de um sistema de gestão integrado da qualidade e SSO (CELIK, 2009; PHENG; PONG, 2003). O próximo tópico discute a questão dos sistemas de gestão integrados.

\section{Sistemas de gestão integrados}

Em administração, o conceito de integração geralmente refere-se à ideia de alinhamento e unidade de ação entre duas atividades interdependentes (WILKINSON; DALE, 1999). Em geral, a literatura que trata sobre a integração de sistemas de gestão distingue dois níveis de integração: alinhamento, no qual as similaridades entre as normas são utilizadas para estruturar o sistema, mas procedimentos separados para cada norma são mantidos; e integração, no qual ocorre a integração completa de procedimentos relevantes e instruções de trabalho (JORGENSEN; REMMEN; MELLADO, 2006; WILKINSON; DALE, 2001).

Entretanto, o trabalho de Jorgensen, Remmen e Mellado (2006) vai além, argumentando ser possível distinguir até mesmo três diferentes níveis de integração. No primeiro nível, são observadas as compatibilidades entre os sistemas de gestão paralelos; no segundo nível ocorre a coordenação entre processos genéricos, focando tarefas do ciclo de gestão; e, finalmente, o terceiro nível de integração é caracterizado por uma cultura organizacional de aprendizado, melhoria contínua do desempenho e envolvimento dos stakeholders nos desafios internos e externos do sistema de gestão integrado. Ainda sobre níveis de integração, o trabalho de Simon, Karapetrovic e Casadesus (2012) trata da questão dos níveis de integração sobre outro aspecto, neste caso do nível de integração dos diferentes elementos que compõem 
um sistema de gestão integrado, como recursos, documentação, metas, procedimentos, entre outros. Outros trabalhos, como o de Jonker e Karapetrovic (2004) apresentam modelos para a integração dos requisitos de sistemas de gestão. No caso dos autores, o modelo apresentado baseia-se em três elementos genéricos de gestão: processos, recursos e objetivos. Já Zeng, Shi e Lou (2007) propuseram o que os autores chamaram de um modelo sinergético de integração, no qual três níveis de integração são definidos. Eles argumentam que a integração de procedimentos, instruções de trabalho e registros (nível mais baixo) dependem da integração relacionada a recursos e a elementos estruturais e culturais. Já os outros dois níveis de integração dependem da integração da estratégia, objetivos e planejamento.

Outro aspecto importante é o método utilizado para guiar as empresas durante o processo de integração dos sistemas de gestão. De maneira geral, a implementação de um sistema de gestão integrado pode ocorrer de duas maneiras. Na primeira, a empresa já possui um sistema de gestão e deseja implementar e integrar outro sistema de gestão. Outra situação é quando a empresa não possui nenhum sistema de gestão implementado e planeja implementar um sistema de gestão integrado desde o início. Labodova (2004) propõe um método para a implementação direta de um sistema de gestão integrado, o qual consiste de sete passos e da utilização de uma matriz de análise de riscos. Basicamente, os sete passos são: descrição do sistema produtivo e do ambiente ao seu redor; identificação de fontes de perigo e possíveis objetivos dos sistemas; combinação de cenários de recursos e objetivos; avaliação do risco, utilizando uma matriz de riscos versus consequências e gerenciamento dos riscos.

Em geral, a literatura sugere que a implementação de sistemas de gestão integrados envolve alinhamento entre as normas de sistemas de gestão (SIMON; KARAPETROVIC; CASADESUS, 2012; WILKINSON; DALE, 2010) e consolidação de objetivos, políticas, procedimentos, gerenciamento de recursos e análise crítica. De qualquer forma, a literatura pesquisada não propõe um modelo de sistema de gestão integrado e processo de implementação coletiva para pequenas e médias empresas localizadas em aglomerados industriais.

\section{Método de pesquisa}

De forma a atender ao objetivo estabelecido, o processo de pesquisa foi dividido em três fases, conforme apresentado na Figura 2. Cada uma delas empregou uma abordagem de pesquisa específica.

O principal objetivo da Fase 1 foi a realização de uma revisão da literatura de forma a adquirir o conhecimento necessário para a definição do programa de qualificação em gestão da qualidade, segurança e saúde ocupacional. A fase II, que engloba toda a estruturação do programa de qualificação, consiste da contribuição teórica (WHETTEN, 1989) desta pesquisa. Para a execução desta fase, os pesquisadores se basearam na literatura pesquisada de forma que fosse possível propor um modelo de um sistema de gestão integrado e um processo para implementação e auditoria deste sistema.

Na fase III foi adotado o método da pesquisa-ação (COUGHLAN; COUGHLAN, 2002) para o planejamento, desenvolvimento e avaliação da

\begin{tabular}{|c|c|}
\hline $\begin{array}{l}\text { Fase I } \\
\text { Revisão da literatura }\end{array}$ & $\begin{array}{l}\quad \text { Revisão da literatura } \\
\text { - Normas de gestão da qualidade e SSO } \\
\text { - Sistemas de Gestão Integrados } \\
\text { - Clusters }\end{array}$ \\
\hline \multirow[b]{2}{*}{$\begin{array}{l}\text { Fase II } \\
\text { Contribuição conceitual } \\
\text { e teórica }\end{array}$} & $\downarrow$ \\
\hline & $\begin{array}{l}\text { Programa de qualificação em Gestão da } \\
\text { Qualidade e Segurança e Saúde Ocupacional } \\
\text { - Modelo de Sistema de Gestão Integrado } \\
\text { - Método para implementação e auditoria }\end{array}$ \\
\hline \multirow{3}{*}{$\begin{array}{l}\text { Fase III } \\
\text { Pesquisa ação } \\
\text { (aplicação piloto) }\end{array}$} & Planejamento da aplicação piloto \\
\hline & $\frac{\Downarrow}{\text { Implementação e auditoria do SGI nas PME's }}$ \\
\hline & $\begin{array}{c}\mathrm{V} \\
\text { Análise dos resultados e proposta final do } \\
\text { programa de qualificação }\end{array}$ \\
\hline
\end{tabular}

Figura 2. Descrição do método de pesquisa. Fonte: elaborado pelos autores. 
aplicação piloto do programa de qualificação, a qual envolveu um grupo de nove pequenas e médias empresas do aglomerado metal-mecânico de Sertãozinho. A pesquisa-ação é um tipo de investigação-ação, termo genérico para qualquer processo que siga um ciclo de aprimoramento da prática utilizando-se de uma investigação sistemática que ocorre por meio de etapas de investigação e ação. Dessa forma, conforme pode ser observado na Figura 2, o processo se inicia com a etapa de planejamento da aplicação piloto (que visa listar as atividades necessárias para a melhoria da prática), seguido da implementação e auditoria do SGI nas PMEs (de forma que a nova prática desejada seja devidamente implementada) e termina com a análise dos resultados e proposta final do programa de qualificação (fase em que os efeitos da ação são analisados e os seus resultados descritos). Assim, observa-se que o desenvolvimento desta pesquisa englobou todas as fases do ciclo de investigação-ação: planejamento de melhor prática, implementação da melhoria desejada, análise e descrição dos resultados da ação (TRIPP, 2005).

O desenvolvimento da Fase III possibilitou a participação efetiva dos pesquisadores, que colaboraram com a agência de coordenação no auxílio às empresas durante a implementação e auditoria do sistema de gestão integrado. Isso permitiu que os pesquisadores refletissem sobre o programa de qualificação proposto, o que possibilitou melhoria do modelo de implementação e processo de auditoria. Este ciclo de pesquisa terminou com a proposta final do programa de qualificação que foi detalhado em um documento que descreve toda a estrutura necessária para o funcionamento do programa, como as pessoas e recursos financeiros necessários para a sua operacionalização e estrutura documental (que inclui um manual do sistema de gestão integrado, procedimentos, registros e material para a realização de treinamentos). Este documento com a proposta final do programa de qualificação e toda a estrutura documental elaborada foi entregue à agência de coordenação do aglomerado, de forma que o programa de qualificação pudesse ter continuidade ao final da realização do projeto de pesquisa. No próximo tópico, esta proposta é brevemente apresentada.

\section{Proposta de um programa de qualificação em gestão da qualidade e segurança e saúde ocupacional}

O programa de qualificação, que será descrito nesta seção, foi proposto para ser executado por uma agência de coordenação que deve gerenciar as atividades de implementação e auditoria periódica do sistema de gestão integrado de forma a verificar a sua implementação efetiva pelas empresas. A Figura 3 mostra uma visão geral da estrutura do programa de qualificação.

Conforme se observa na figura, o programa de qualificação proposto parte de um modelo de sistema de gestão integrado, composto de vários critérios de gestão, que foram distribuídos em diversas fases para que sua implementação nas empresas ocorresse de maneira gradual. Estes critérios são apresentados na seção 5.1. Para a condução da implementação do modelo de sistema de gestão, foram definidos

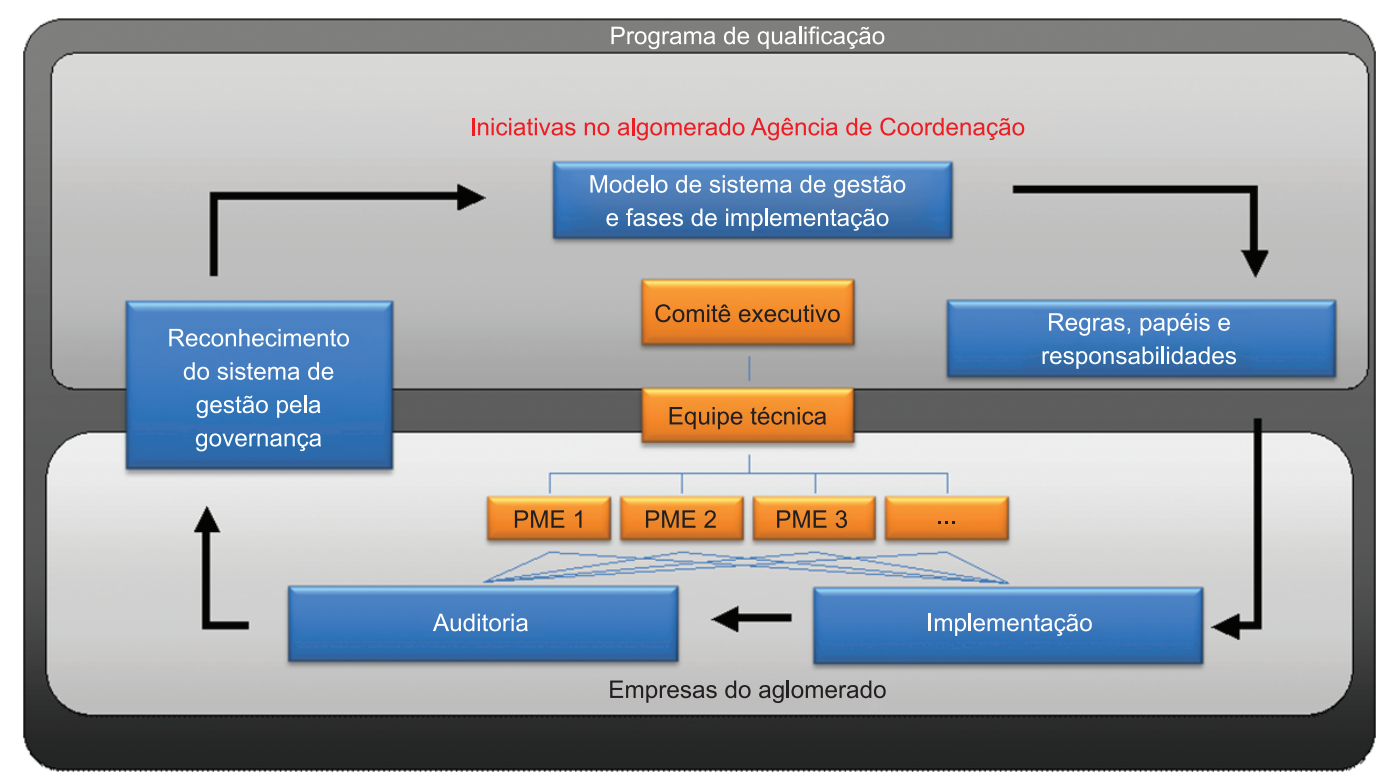

Figura 3. Programa de qualificação em gestão da qualidade e segurança e saúde ocupacional. Fonte: elaborado pelos autores. 
papéis e responsabilidades tanto das empresas, que implementam o sistema de gestão integrado, quanto da agência de coordenação, que gerencia o programa e auxilia as empresas no processo de implementação.

Depois de definidos os papéis e responsabilidades, ocorre a implementação do sistema de gestão e, posteriormente, as empresas devem passar por um processo de auditoria. Se aprovadas, as empresas são reconhecidas pela agência de coordenação por meio da emissão de um selo que atesta que a empresa implementou de maneira efetiva os critérios de gestão da qualidade, segurança e saúde ocupacional propostos pelo programa de qualificação. Depois desta etapa, novas empresas podem ingressar no programa de qualificação e elas deverão passar por todas as etapas citadas anteriormente.

Outro aspecto importante do programa de qualificação, que também é representado na Figura 3, é a existência de um comitê executivo formado por membros da agência de coordenação e outras partes interessadas, como representantes de grandes empresas locais e universidades. Seu principal papel é a definição de diretrizes estratégicas, identificação de oportunidades de melhoria no programa e sua disseminação para a comunidade local. Este comitê executivo é responsável pela organização e manutenção de uma equipe técnica, que tem como papel auxiliar as empresas no processo de implementação do sistema de gestão integrado. Esta equipe técnica deve ser formada por profissionais qualificados e que possuam experiência na implementação de sistemas de gestão. Esses profissionais, além de auxiliar as empresas no processo de implementação do sistema de gestão integrado, realizam auditorias internas e preparam as empresas para a auditoria externa. $\mathrm{O}$ próximo tópico detalha os critérios do sistema de gestão integrado proposto.

\subsection{Critérios do sistema de gestão integrado de qualidade, segurança e saúde ocupacional}

Conforme descrito anteriormente, uma das fases para a execução do programa de qualificação consiste na implementação dos critérios do sistema de gestão integrado. A Figura 4 apresenta um modelo que visa

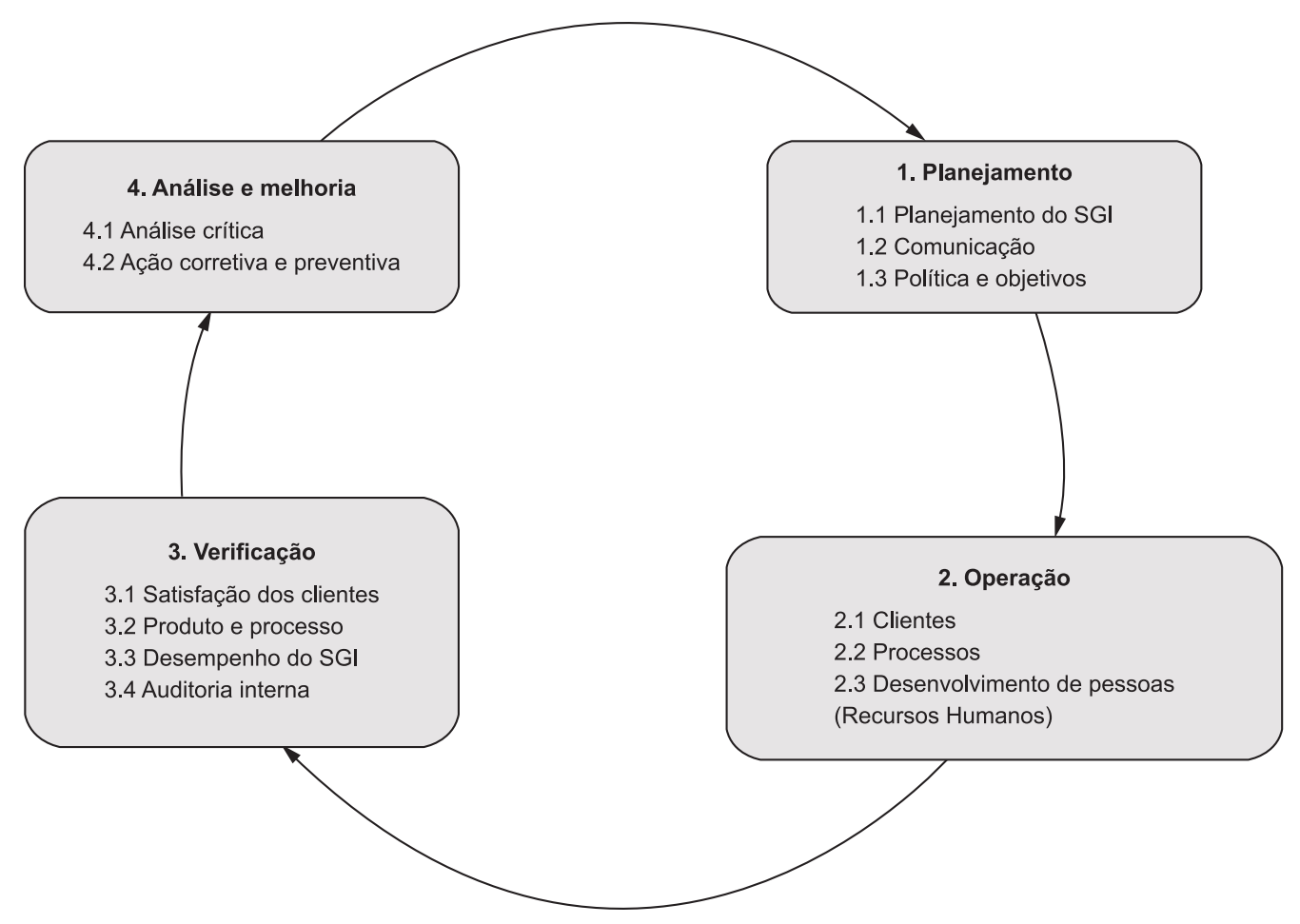

Figura 4. Modelo de Sistema de Gestão Integrado. Fonte: elaborado pelos autores. 
direcionar o processo de implementação do sistema de gestão proposto.

Este modelo é estruturado em quatro grandes etapas: planejamento, operação, verificação e análise. Esta estrutura é baseada no princípio de que um sistema de gestão deve ser implementado por meio de um ciclo de melhoria de planejamento, implementação, verificação e análise crítica. Esta ideia está alinhada com as normas ISO 9001 e ISO 14001 bem como com o modelo de gestão da OHSAS 18001. Note ainda que o modelo de sistema de gestão integrado utilizado corresponde ao ciclo PDCA, sendo que o $\mathrm{P}($ Plan) refere-se ao planejamento, o D (Do) refere-se à operação, o C (Control) refere-se à verificação e o $\mathrm{A}(A c t)$ refere-se à análise e melhoria. Neste ponto, é importante ressaltar que o modelo para a integração dos sistemas de gestão e sua implementação não foi integralmente realizado de acordo com nenhum dos trabalhos discutidos na revisão bibliográfica. Entretanto, alguns pontos sugeridos na literatura para a implementação de sistemas de gestão integrados foram seguidos, como, por exemplo: alinhamento e consolidação das políticas, dos objetivos, dos procedimentos e da análise crítica.

Os critérios do sistema de gestão integrado são apresentados no Quadro 1. Estes foram estruturados de forma a alinhar os requisitos das normas ISO 9001 e OHSAS 18001 e de forma a seguir o modelo de sistema de gestão integrado proposto e apresentado na Figura 4. Dessa forma, este quadro possibilita também a visualização das correspondências entre essas normas.

É importante ressaltar que todos os requisitos das normas ISO 9001 e OHSAS 18001 foram considerados para a composição dos critérios do sistema de gestão integrado proposto. Entretanto, conforme pode ser verificado no Quadro 2, vários requisitos das normas ISO 9001 e OHSAS 18001 foram classificados como opcionais. Isso ocorreu porque o programa de qualificação foi criado de forma que as empresas pudessem implementar o sistema de gestão integrado em etapas e, após a análise das empresas e das necessidades do mercado em que elas se encontram inseridas, foram escolhidos os critérios que necessitavam ser implementados com maior urgência. Entretanto, os critérios classificados como opcionais não foram excluídos do programa de qualificação, mas tiveram o prazo para a sua implementação estendido até a próxima auditoria (que deveria ocorrer um ano após a realização da primeira auditoria).

Para a implementação dos requisitos do sistema de gestão integrado apresentados anteriormente, deve-se realizar, em cada fase de implementação (as quais serão apresentadas posteriormente no Quadro 3), as seguintes atividades:
- Treinamento nos critérios do sistema de gestão e nos requisitos das normas;

- Implementação dos procedimentos e registros; e

- Verificação do progresso da implementação.

O treinamento nos critérios do sistema de gestão e nos requisitos das normas deve ser organizado pela agência de coordenação e ser conduzido pelos profissionais que compõem a equipe técnica do programa de qualificação. Assim, cada treinamento deve ser conduzido por pessoal capacitado antes da implementação dos critérios de gestão. Depois da realização do treinamento, os procedimentos e registros referentes ao conjunto de critérios que foram abordados no treinamento devem ser implementados em cada organização, o que deve contar mais uma vez com a participação da equipe técnica, que auxiliará as empresas neste processo.

Por fim, deve-se verificar o progresso da implementação daquele determinado bloco de critérios de gestão, o que deve ser feito por meio da realização de auditorias internas pela equipe técnica. Depois da realização destas auditorias internas, planos de ação devem ser gerados para que as não conformidades encontradas possam ser tratadas pelas empresas.

O Quadro 3 apresenta toda a documentação desenvolvida para ser implementada nas organizações. Esta documentação abrange os critérios que compõem as quatro etapas do modelo de sistema de gestão integrado apresentado anteriormente: planejamento, operação, verificação e análise e melhoria. É importante ressaltar que, para que a implementação dos critérios do sistema de gestão integrado ocorresse de maneira mais gradual, as quatro etapas do modelo de sistema de gestão integrado foram distribuídas em cinco fases de implementação. Assim, as empresas têm mais tempo para implementar os critérios de gestão de maneira satisfatória.

Por fim, após a implementação de todos os critérios do sistema de gestão integrado, as empresas devem passar pelo processo de auditoria externa para o recebimento pela agência de coordenação do reconhecimento da implementação adequada do sistema de gestão integrado. Para a realização desta auditoria, foi elaborado um procedimento para a seleção de auditores externos, o qual deve ser executado pela agência de coordenação, e também um formulário para o registro das auditorias. Neste formulário, devem ser indicadas as não conformidades encontradas, as ações corretivas a serem realizadas pela empresa auditada e também a indicação ou não para o recebimento pela empresa do reconhecimento da implementação adequada do sistema de gestão integrado pela agência de coordenação local. Apresentada a proposta para a implementação de um sistema de gestão integrado em aglomerados industriais, a próxima seção apresenta a aplicação piloto realizada para testar tal proposta. Vale ressaltar 
Quadro 1. Critérios obrigatórios do sistema de gestão integrado.

\begin{tabular}{|c|c|}
\hline Critérios do sistema de gestão integrado & $\begin{array}{c}\text { Requisitos das normas } \\
\text { (ISO 9001:2008/OHSAS18001:2007) }\end{array}$ \\
\hline \multicolumn{2}{|l|}{1 Planejamento } \\
\hline \multicolumn{2}{|l|}{ 1.1 Sistema de Gestão Integrado } \\
\hline 1.1.1 Requisitos Gerais & 4.1 ISO/4.1 OHSAS \\
\hline 1.1.2 Representante da Direção & 5.5.2 ISO \\
\hline \multicolumn{2}{|l|}{1.2 Comunicação } \\
\hline 1.2.1 Requisitos de documentação & 4.2.1 ISO/4.4.4 OHSAS \\
\hline 1.2.2 Manual da qualidade e SSO & 4.2.2 ISO \\
\hline 1.2.3 Responsabilidade e autoridade & 5.5.1 ISO/4.4.1 OHSAS \\
\hline 1.2.4 Controle de documentos & 4.2.3 ISO/4.4.5 OHSAS \\
\hline 1.2.5 Controle de registros & 4.2.4 ISO/4.5.4 OHSAS \\
\hline 1.2.6 Comunicação Interna & 5.5.3 ISO/4.4.3.1 OHSAS \\
\hline \multicolumn{2}{|l|}{ 1.3 Planejamento da qualidade e SSO } \\
\hline 1.3.1 Política integrada de qualidade e SSO & 5.3 ISO/4.2 OHSAS \\
\hline 1.3.2 Objetivos e metas de qualidade e SSO & 5.4.1 ISO/4.3.3 OHSAS \\
\hline $\begin{array}{l}\text { 1.3.3 Identificação de perigos, avaliação de riscos e } \\
\text { determinação de controles }\end{array}$ & 4.3.1 OHSAS \\
\hline 1.3.4 Informação - requisitos legais e outros & 4.3.2 OHSAS \\
\hline \multicolumn{2}{|l|}{2 Realização do produto e recursos humanos } \\
\hline \multicolumn{2}{|l|}{ 2.1 Clientes } \\
\hline 2.1.1 Determinação dos requisitos relacionados ao produto & 7.2.1 ISO/4.4.6 OHSAS \\
\hline 2.1.2 Análise dos requisitos relacionados ao produto & 7.2.2 ISO/4.46 OHSAS \\
\hline 2.1.3 Propriedade do cliente & 7.5.4 ISO \\
\hline \multicolumn{2}{|l|}{ 2.2 Processos } \\
\hline 2.2.1 Projeto e desenvolvimento & $7.3 \mathrm{ISO}$ \\
\hline 2.2.2 Processo de Aquisição & 7.4.1 ISO/4.4.6 OHSAS \\
\hline 2.2.3 Informações de aquisição & 7.4.2 ISO/4.4.6 OHSAS \\
\hline 2.2.4 Verificação do produto adquirido & 7.4.3 ISO/4.4.6 OHSAS \\
\hline 2.2.5 Controle da produção e prestação de serviços & 7.5.1 ISO/4.4.6 OHSAS \\
\hline 2.2.6 Identificação e rastreabilidade & 7.5.3 ISO \\
\hline $\begin{array}{l}\text { 2.2.7 Controle e monitoramento de instrumentos de } \\
\text { medição }\end{array}$ & 7.6 ISO/4.5.1 OHSAS \\
\hline \multicolumn{2}{|l|}{ 2.3 Recursos Humanos, segurança e saúde ocupacional } \\
\hline 2.3.1 Competência, treinamento e conscientização & 6.2.2 ISO/4.4.2 OHSAS \\
\hline 2.3.2 Preparação e atendimento a emergências & 4.4.7 OHSAS \\
\hline \multicolumn{2}{|l|}{3 Verificação } \\
\hline \multicolumn{2}{|c|}{\begin{tabular}{|l|l|} 
3.1 Satisfação dos clientes & \\
\end{tabular}} \\
\hline 3.1.1 Monitoramento e medição da satisfação dos clientes & 8.2.1 ISO \\
\hline \multicolumn{2}{|c|}{ 3.2 Monitoramento e medição de produtos e processos } \\
\hline 3.2.1 Controle de produto não conforme & 8.3 ISO \\
\hline \multicolumn{2}{|c|}{\begin{tabular}{|l|l|} 
3.3 Desempenho de SSO & \\
\end{tabular}} \\
\hline 3.3.1 Avaliação da conformidade com os requisitos legais & 4.5.2 OHSAS \\
\hline 3.3.2 Investigação de acidentes & 4.5.3 OHSAS \\
\hline \multicolumn{2}{|l|}{4 Análise crítica e melhoria contínua } \\
\hline \multicolumn{2}{|l|}{ 4.1 Análise crítica } \\
\hline 4.1.1 Análise crítica da alta direção & 5.6 ISO/4.6 OHSAS \\
\hline \multicolumn{2}{|l|}{ 4.2 Melhoria contínua } \\
\hline 4.2.1 Ação corretiva & 8.5.2 ISO/4.5.3.2 OHSAS \\
\hline
\end{tabular}

Fonte: Elaborado pelos autores. 
Quadro 2. Critérios opcionais do sistema de gestão integrado.

\begin{tabular}{|l|l|}
\hline \multicolumn{1}{|c|}{ Critérios opcionais do sistema de gestão integrado } & \multicolumn{1}{c|}{$\begin{array}{c}\text { Requisitos das normas } \\
\text { (ISO9001:2008/OHSAS18001:2007) }\end{array}$} \\
\hline 1.3 Planejamento da qualidade e SSO & 6.3 ISO/4.4.1 OHSAS \\
\hline Infraestrutura para qualidade e SSO & 6.4 ISO \\
\hline Ambiente de trabalho & 4.4 .3 .2 OHSAS \\
\hline Participação e consulta & \\
\hline 2 Realização do produto e recursos humanos & 7.2 .3 ISO/4.4.3 OHSAS \\
\hline 2.1 Clientes & \\
\hline Comunicação com o cliente & 7.1 ISO/4.4.6 OHSAS \\
\hline 2.2 Processos & 7.5 .5 ISO/4.4.6 OHSAS \\
\hline Planejamento da realização do produto & \\
\hline Preservação do produto & 6.2 ISO \\
\hline 2.3 Recursos Humanos, segurança e saúde ocupacional & $6.2 .2(\mathrm{c})$ ISO/4.4.2 OHSAS \\
\hline Recursos humanos & \\
\hline Avaliação da eficácia das ações executadas & \\
\hline 3 Verificação & 8.2 .3 ISO \\
\hline 3.2 Monitoramento e medição de produtos e processos & \\
\hline Monitoramento e medição de processos & 4.5 .1 OHSAS \\
\hline 3.3 Desempenho de SSO & \\
\hline Monitoramento e medição do desempenho de SSO & 8.2 .2 ISO/4.5.5 OHSAS \\
\hline 3.4 Auditoria Interna & 8.5 .3 ISO/4.5.3.2 OHSAS \\
\hline Auditoria interna do sistema de gestão integrado & \\
\hline 4.2 Melhoria contínua & \\
\hline Ação preventiva & \\
\hline
\end{tabular}

Fonte: Elaborado pelos autores.

que a proposta apresentada trata-se da versão final, a qual recebeu alguns ajustes após a aplicação piloto realizada e detalhada a seguir.

\section{Aplicação piloto em um aglomerado metal-mecânico}

A proposta inicial do programa de qualificação em gestão da qualidade, Segurança e Saúde Ocupacional (SSO), apresentada na seção 5, foi aplicada em um grupo de pequenas e médias empresas durante a realização de um programa piloto de qualificação no aglomerado metal-mecânico de Sertãozinho - São Paulo. Dados do Instituto Brasileiro de Geografia e Estatística (INSTITUTO..., 2009) mostram que existem cerca de 540 empresas no aglomerado metal-mecânico de Sertãozinho, as quais empregam cerca de 15.000 pessoas. Cerca de $90 \%$ dessas empresas fabricam componentes utilizados no processo produtivo do etanol e na geração de energia, bem como equipamentos utilizados na preparação do solo, plantio, limpeza, fertilização, colheita e transporte da cana-de-açúcar.

A associação local de empresas, chamada CEISE, a qual é a principal coordenadora das iniciativas do aglomerado, motivada pelas demandas de empresas associadas por auxílio a questões inerentes à gestão da qualidade e de SSO, decidiu participar de uma iniciativa em parceria com pesquisadores para o desenvolvimento de um programa de qualificação em gestão da qualidade e de SSO.

O programa de qualificação proposto para o aglomerado de Sertãozinho foi planejado para ser um serviço fornecido pelo CEISE. Assim, este serviço consiste em prover assistência às empresas na implementação e auditoria de um sistema de gestão integrado de qualidade e SSO, o qual possui como objetivo final qualificar as empresas que provarem, por meio de um processo de auditoria, possuir um sistema de gestão implementado de maneira efetiva. $\mathrm{O}$ programa de qualificação é apresentado pelo CEISE e divulgado no aglomerado como "Selo da Qualidade".

Um dos principais objetivos deste programa é disseminar a cultura da qualidade e melhorar a competência das pequenas e médias empresas do aglomerado em gerenciar aspectos relacionados à qualidade e SSO, reduzindo não conformidades, acidentes e ineficiências, melhorando a sua competitividade. Vale ressaltar que o objetivo do programa de qualificação não é substituir as certificações ISO 9001 e OHSAS 18001, mas sim oferecer um programa de qualificação que possa 
Quadro 3. Fases do processo de implementação do sistema de gestão integrado.

\begin{tabular}{|c|c|c|}
\hline Fase & Atividades & Documentação desenvolvida \\
\hline 1 & $\begin{array}{l}\text { Treinamento, implementação } \\
\text { e verificação dos requisitos: } \\
\text { 1. Planejamento } \\
\text { 1.2 Comunicação } \\
\text { 1.3 Planejamento da } \\
\text { qualidade e SSO }\end{array}$ & $\begin{array}{l}\text { - Procedimentos } \\
\text { - Controle de documentos e registros } \\
\text { - Comunicação } \\
\text { - Formulários } \\
\text { - Lista Mestra } \\
\text { - Objetivos e Metas da Qualidade e SSO } \\
\text { - Outros formulários relacionados aos procedimentos estabelecidos } \\
\text { - Elaboração do Manual da Qualidade e SSO: mapeamento de processos, } \\
\text { organograma, requisitos de planejamento do sistema de gestão (política } \\
\text { e objetivos). Obs.: o texto do Manual da Qualidade e SSO foi elaborado } \\
\text { conforme a implementação dos conjuntos de critérios. Dessa forma, sua } \\
\text { elaboração só é concluída ao final da quinta etapa. }\end{array}$ \\
\hline Fase & Atividades & Documentação desenvolvida \\
\hline 2 & $\begin{array}{l}\text { Treinamento, implementação } \\
\text { e verificação dos requisitos: } \\
\text { 2. Operação } \\
\text { 2.1 Clientes }\end{array}$ & $\begin{array}{l}\text { - Procedimento para identificação de aspectos legais } \\
\text { - Formulários } \\
\text { - Cadastro da propriedade do cliente } \\
\text { - Identificação e avaliação de conformidade com os requisitos legais } \\
\text { - Requisitos relacionados ao produto e atendimento de pedidos } \\
\text { - Outros formulários relacionados aos procedimentos estabelecidos } \\
\text { - Atualização do Manual: processos relacionadas a clientes e requisitos } \\
\text { relacionados ao produto }\end{array}$ \\
\hline Fase & Atividades & Documentação desenvolvida \\
\hline 3 & $\begin{array}{l}\text { Treinamento, implementação } \\
\text { e verificação dos requisitos: } \\
\text { 2. Operação } \\
\text { 2.2 Processos e } \\
\text { Desenvolvimento de Pessoas }\end{array}$ & $\begin{array}{l}\text { - Procedimento para Projeto e Desenvolvimento } \\
\text { - Formulários } \\
\text { - Controle de equipamentos de medição e monitoramento } \\
\text { - Proposta de projeto e desenvolvimento } \\
\text { - Outros formulários relacionados aos procedimentos estabelecidos } \\
\text { - Descrição de Cargos } \\
\text { - Avaliação de Competências } \\
\text { - Atualização do Manual: planejamento da realização do produto, controle } \\
\text { da produção e prestação de serviço, determinação de requisitos sobre } \\
\text { propriedade do cliente, identificação e rastreabilidade e competência, } \\
\text { treinamento e conscientização }\end{array}$ \\
\hline Fase & Atividades & Documentação desenvolvida \\
\hline 4 & $\begin{array}{l}\text { Treinamento, implementação } \\
\text { e verificação dos requisitos: } \\
\text { 2. Operação } \\
\text { 2.3 Aquisição } \\
\text { 2.4 Segurança e saúde } \\
\text { ocupacional }\end{array}$ & $\begin{array}{l}\text { - Procedimentos } \\
\text { - Aquisição } \\
\text { - Atendimento de emergências } \\
\text { - Identificação de perigos, avaliação de riscos e determinação de controles } \\
\text { - Formulários } \\
\text { - Comunicação de perigos e riscos de SSO } \\
\text { - Outros formulários relacionados aos procedimentos estabelecidos } \\
\text { - Atualização do manual: ambiente de trabalho }\end{array}$ \\
\hline Fase & Atividades & Documentação desenvolvida \\
\hline 5 & $\begin{array}{l}\text { Treinamento, implementação } \\
\text { e verificação dos requisitos: } \\
\text { 3. Monitoramento e medição } \\
\text { 4. Análise Crítica }\end{array}$ & $\begin{array}{l}\text { - Procedimentos } \\
\text { - Investigação de acidentes } \\
\text { - Controle de produto não conforme e ação corretiva/preventiva } \\
\text { - Formulários } \\
\text { - Ata de análise crítica } \\
\text { - Satisfação do Cliente } \\
\text { - Outros formulários relacionados aos procedimentos estabelecidos } \\
\text { - Atualização do manual: satisfação dos clientes, desempenho de SSO, } \\
\text { melhoria contínua e análise }\end{array}$ \\
\hline
\end{tabular}

Fonte: Elaborado pelos autores. 
ser visto como um primeiro passo rumo a estas certificações.

A aplicação piloto iniciou-se com a definição de um grupo de empresas interessadas em fazer parte do programa de qualificação. Depois da realização de algumas reuniões com este grupo de empresas no escritório do CEISE, nas quais os objetivos e o plano de atividades foram apresentados, um grupo de nove empresas foi estabelecido.

O comitê executivo para esta aplicação piloto foi formado por membros da agência de coordenação do aglomerado, dois membros de grandes empresas da região de Sertãozinho, um consultor local e um membro da universidade. A equipe técnica foi formada por um membro da agência de coordenação, um consultor técnico local e por um aluno de mestrado acadêmico. A equipe de gestão do projeto foi formada por um gerente de projetos, um estudante de graduação e um assistente administrativo da agência de coordenação. Quatro alunos de graduação treinados auxiliaram os facilitadores das PMEs na implementação do sistema de gestão, juntamente com consultores e com o aluno de mestrado. A Figura 5 ilustra os papéis e responsabilidades dos participantes da aplicação piloto, conforme descrito anteriormente.

Oito das nove empresas participantes da aplicação piloto eram fabricantes de máquinas, equipamentos ou componentes, sendo a maior parte destas empresas fornecedoras de usinas de açúcar e álcool. O Quadro 4 apresenta uma breve descrição destas empresas.

A aplicação piloto nas empresas iniciou-se em Novembro de 2009 após o detalhamento, em reuniões, das ações e prazos a serem cumpridos. Os treinamentos ocorreram no escritório do CEISE entre os meses de Novembro/09 e Abril/10 e contaram com a participação dos representantes das empresas e dos alunos de graduação envolvidos no desenvolvimento do projeto. A Figura 6 mostra a quantidade de treinamentos realizados e o número de pessoas treinadas em cada um deles. Esta figura também mostra o número de pessoas que foram treinadas para realizar as auditorias finais nas empresas participantes do programa de qualificação.

Depois de participarem dos treinamentos, os representantes das empresas receberam auxílio dos pesquisadores da equipe do projeto (equipe técnica e alunos de graduação treinados) na implementação do sistema de gestão. Depois do treinamento e implementação referentes a cada fase (apresentadas anteriormente no Quadro 3), os coordenadores técnicos do programa eram responsáveis por verificar até que ponto as empresas haviam evoluído no processo de implementação, o que foi realizado por meio da condução de auditorias internas após o término de cada fase de implementação.

Das nove empresas que iniciaram o processo de implementação, quatro desistiram durante o processo,

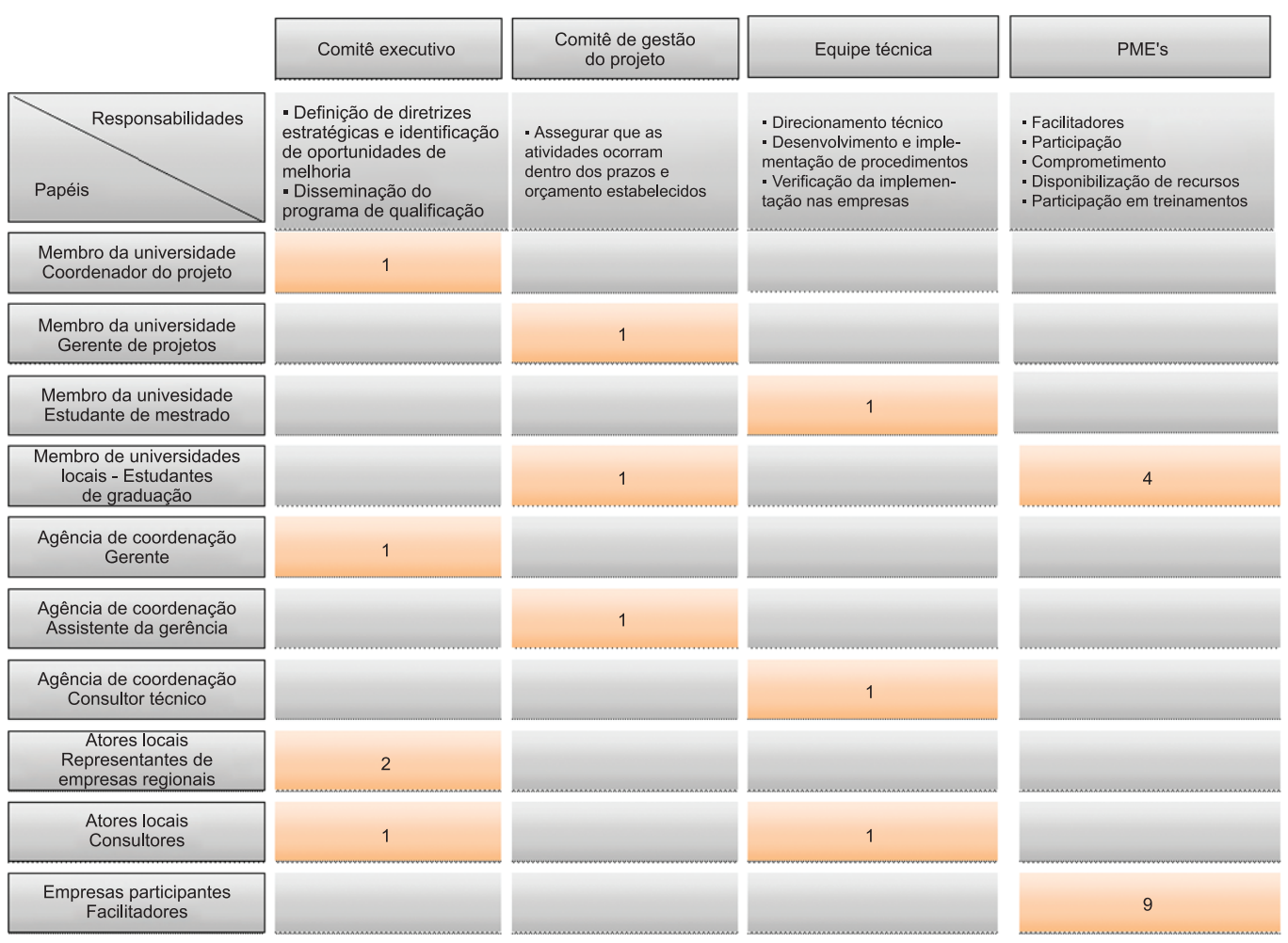

Figura 5. Papéis e responsabilidades durante a aplicação piloto. Fonte: elaborado pelos autores. 
Quadro 4. Empresas participantes da aplicação piloto.

\begin{tabular}{|c|c|c|}
\hline Empresa & Principais atividades & $\mathrm{N}^{0}$ de empregados \\
\hline A & $\begin{array}{l}\text { Automação de equipamentos. Principais produtos: controle para turbinas a vapor, } \\
\text { softwares e gateways. }\end{array}$ & 70 \\
\hline $\mathrm{B}$ & $\begin{array}{l}\text { Fabricante de equipamentos para o setor metal-mecânico. Principais produtos: } \\
\text { peneiras rotativas, ventiladores e exaustores. }\end{array}$ & 48 \\
\hline $\mathrm{C}$ & $\begin{array}{l}\text { Fabricante de equipamentos para o setor metal-mecânico. Principais produtos: } \\
\text { peneiras rotativas, exaustores, ventiladores, pontes rolantes e equipamentos para } \\
\text { tratamento de caldo. }\end{array}$ & 30 \\
\hline D & $\begin{array}{l}\text { Fabricante de tanques e tubos de fibra e prestadora de serviços. Principais produtos: } \\
\text { tanques para transporte de vinhaça e tubulações em PRFV. }\end{array}$ & 54 \\
\hline $\mathrm{E}$ & $\begin{array}{l}\text { Fabricante de equipamentos para o setor metal-mecânico e prestador de serviços. } \\
\text { Principais produtos: distribuidores e sistemas de lubrificação. }\end{array}$ & 28 \\
\hline $\mathrm{F}$ & $\begin{array}{l}\text { Fabricação de peças fundidas. Principais produtos: mancais para moendas, roldanas } \\
\text { e semicasquilhos. }\end{array}$ & 120 \\
\hline $\mathrm{G}$ & $\begin{array}{l}\text { Fabricante de equipamentos para o setor metal-mecânico. Principais produtos: } \\
\text { palitos de transmissão, espalhador, martelo desfibrador, acoplamento. }\end{array}$ & 25 \\
\hline $\mathrm{H}$ & $\begin{array}{l}\text { Serviços de manutenção e fabricante de acessórios. Principais produtos: selo } \\
\text { mecânico e uniões rotativas. }\end{array}$ & 23 \\
\hline I & $\begin{array}{l}\text { Fabricante de equipamentos para o setor metal-mecânico e assistência técnica. } \\
\text { Principais produtos: fabricação e reforma de redutores e engrenagens e fabricação } \\
\text { de peças sob projeto pré-definido ou sob encomenda. }\end{array}$ & 160 \\
\hline
\end{tabular}

Fonte: Elaborado pelos autores.

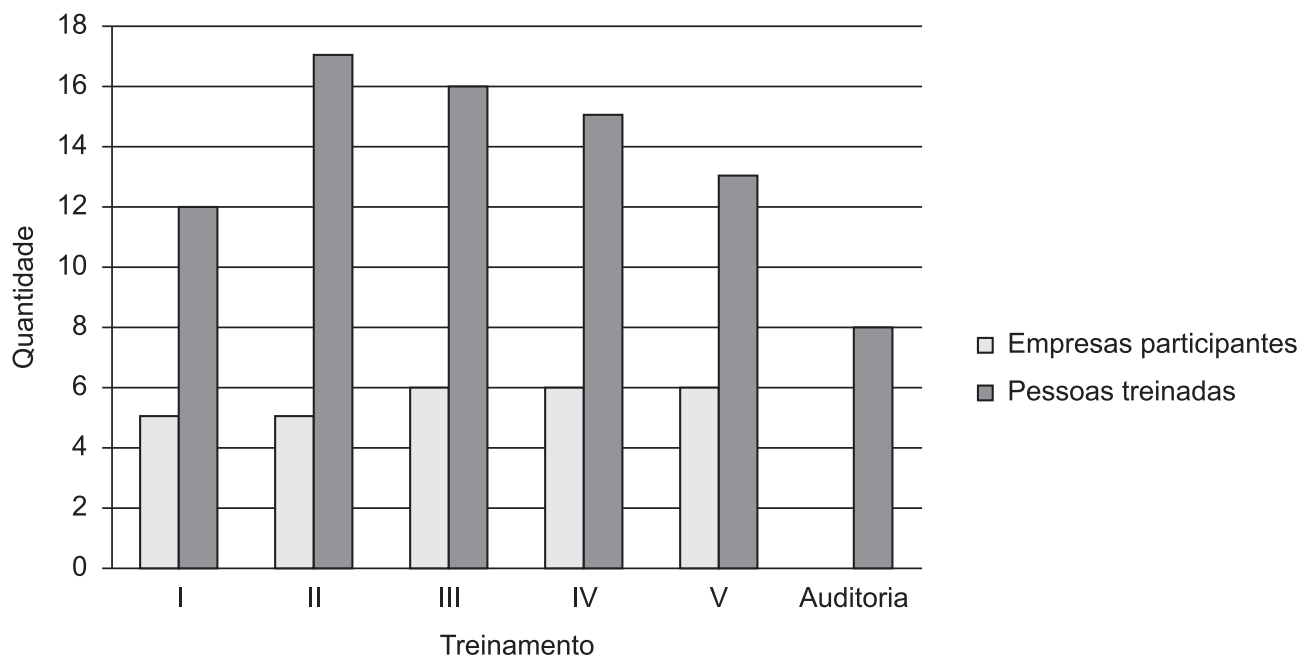

Figura 6. Treinamentos realizados e número de empresas/pessoas treinadas. Elaborado pelos autores.

sendo que quatro das cinco empresas remanescentes completaram a implementação em Junho/2010. A auditoria externa foi realizada nos meses de Julho e Agosto de 2010. Depois da revisão do sistema de gestão, realizada com base no relatório de auditoria, duas empresas foram consideradas qualificadas e aptas a receberem o selo da qualidade, segurança e saúde ocupacional. Já as outras duas empresas foram avaliadas pela equipe de auditoria e orientadas a trabalhar determinados aspectos em seus sistemas para que elas pudessem ser consideradas aptas ao recebimento do selo.
A análise dos resultados obtidos com a aplicação piloto contribuiu para a revisão do programa de qualificação proposto. Esta aplicação também demonstrou a necessidade em desenvolver uma documentação completa sobre o programa, no formato de um manual, detalhando questões como as regras e condições para a participação das empresas, processo de implementação e auditoria e a estrutura necessária para a condução do programa de qualificação. A estrutura do documento elaborado é apresentada no Quadro 5. Este documento permitiu que a agência de coordenação do aglomerado replicasse o programa, 
Quadro 5. Estrutura do documento final do programa de qualificação.

\begin{tabular}{|l|l|}
\hline \multicolumn{1}{|c|}{ Seção } & \multicolumn{1}{c|}{ Objetivo } \\
\hline Apresentação & $\begin{array}{l}\text { Apresentar, em linhas gerais, o programa de qualificação, o organismo de } \\
\text { governança (CEISE) e os potencias benefícios para as empresas que participarem } \\
\text { do programa de qualificação. }\end{array}$ \\
\hline Regras de participação & $\begin{array}{l}\text { Determinar os pré-requisitos necessários para a participação de empresas no } \\
\text { programa de qualificação. } \\
\text { Definir regras de ingresso no programa de qualificação. }\end{array}$ \\
\hline $\begin{array}{l}\text { Passo a passo para a obtenção } \\
\text { do selo da qualidade e SSO }\end{array}$ & $\begin{array}{l}\text { Apresentar o passo a passo para que a empresa seja qualificada no programa } \\
\text { (desde a sua inscrição no programa, passando pelo processo de implementação do } \\
\text { sistema de gestão integrando e finalizando com o processo de auditorias). }\end{array}$ \\
\hline Utilização da marca do selo & $\begin{array}{l}\text { Determina regras para a utilização da marca do selo (para empresas aprovadas no } \\
\text { processo de auditoria), bem como trata de assuntos como validade e renovação } \\
\text { deste selo. }\end{array}$ \\
\hline $\begin{array}{l}\text { Papéis e responsabilidades no } \\
\text { programa de qualificação }\end{array}$ & $\begin{array}{l}\text { Apresenta toda a estrutura de papéis e responsabilidade para a operacionalização } \\
\text { das atividades do programa de qualificação. }\end{array}$ \\
\hline Investimentos demandados & $\begin{array}{l}\text { Investimentos diretos e indiretos para as empresas participantes. } \\
\text { Investimentos que devem ser realizados pela agência de coordenação para o } \\
\text { desenvolvimento do programa de qualificação. }\end{array}$ \\
\hline $\begin{array}{l}\text { Apêndice - Sistema de Gestão } \\
\text { Integrado }\end{array}$ & $\begin{array}{l}\text { Critérios de gestão da qualidade, segurança e saúde ocupacional. } \\
\text { Modelo de sistema de gestão integrado (estrutura documental, processo de } \\
\text { implementação e processo de auditoria). }\end{array}$ \\
\hline
\end{tabular}

Fonte: Elaborado pelos autores.

sendo que, no ano de 2012, aconteceu a segunda rodada de implementação, quando mais empresas ingressaram no programa de qualificação.

Para a realização da segunda rodada do programa de qualificação, a agência de coordenação local contou com uma colaboração menor dos pesquisadores que elaboraram o programa, dado que o objetivo da pesquisa era que a agência se tornasse autossuficiente em sua condução. Para isso, conforme citado anteriormente, os pesquisadores elaboraram toda a documentação necessária para a condução do programa de qualificação pela agência de coordenação e disponibilizaram todos esses documentos em um site que é acessado apenas por intermédio de uma senha.

Além da documentação, a agência de coordenação também deveria montar uma equipe para dar continuidade ao programa. Isso foi feito por meio da contratação de um responsável técnico pelo programa que seria responsável por ministrar os treinamentos e acompanhar, juntamente com outros consultores, as atividades de implementação das empresas.

\section{Considerações finais}

Com a aplicação piloto do programa de qualificação e sua posterior continuidade, observa-se que as empresas do aglomerado estão começando a entender a importância e os potenciais benefícios em participar dessa ação conjunta junto à agência de coordenação local. Existem relatos das empresas, que foram reconhecidas com o selo, de que contratos de fornecimento foram fechados após essas empresas demonstrarem aos seus potenciais clientes sua iniciativa em implementar um sistema de gestão integrado. Outro ganho efetivo do programa de qualificação foi a adequação das empresas à legislação de segurança e saúde ocupacional e a melhoria no controle e redução de acidentes ocupacionais.

A principal dificuldade encontrada durante a realização da aplicação piloto foi o cumprimento dos prazos de implementação pelas empresas participantes. Isso ocorreu porque grande parte das empresas nunca havia tido contato com um sistema de gestão. Outro motivo foi a falta de funcionários disponíveis para a implementação do sistema de gestão integrado, dado que, durante o processo, vários documentos deveriam ser adequados e outros elaborados. Além da falta de recursos humanos, a falta de recursos financeiros também dificultou o processo de implementação, pois a operacionalização de diversos critérios de gestão exigia a realização de investimentos por parte das empresas. Estas dificuldades citadas, falta de recursos humanos e financeiros e falta de conhecimento e experiência com a implementação de sistemas de gestão, também foram identificados por Aggelogiannopoulos, Drosinos e Athanasopoulos (2007) em seu trabalho sobre a implementação de um sistema de gestão da qualidade em algumas empresas.

O desenvolvimento da aplicação piloto do programa de qualificação no aglomerado metal-mecânico de Sertãozinho foi bem recebido pela comunidade local, sendo que várias matérias sobre a realização desta aplicação foram divulgadas em diversos meios 
de comunicação, como revistas especializadas em segurança. Depois da aplicação piloto, outras empresas demonstraram interesse em participar do programa de qualificação, o que evidencia o entendimento dessas empresas sobre os potenciais benefícios do programa.

Entretanto, muitas ações ainda devem ser desenvolvidas para que as empresas do aglomerado percebam as vantagens em serem reconhecidas com o selo da qualidade e segurança. Além dos ajustes que devem ser realizados na estrutura e no desenvolvimento das atividades do programa, o que deve ser realizado pela agência de coordenação durante a realização de novas rodadas de implementação, o aspecto mais desafiador é sua sustentabilidade a longo prazo. Depois da conclusão da aplicação piloto, a agência de coordenação (CEISE) assumiu todas as atividades necessárias para o desenvolvimento do programa de qualificação. Isto incluiu, conforme citado anteriormente, o oferecimento de consultorias para as empresas durante o processo de implementação, a manutenção de uma equipe de auditores e a provisão de serviços de auditorias periódicas.

Portanto, o papel desempenhado pela agência de coordenação é de fundamental importância para a sustentabilidade do programa de qualificação. Por isso, podem ser considerados como fatores de sucesso para a sustentabilidade do programa:

- Sentimento de apropriação do programa pela agência local de coordenação;

- Envolvimento de profissionais locais no programa;

- Comunicação, treinamento e qualificação das empresas;

- Profissionalismo e transparência nos processos de implementação e auditoria;

- Estabelecimento de estrutura e infraestrutura para a realização do programa;

- Definição clara de papéis e responsabilidades para o gerenciamento e operação do programa; e

- Reconhecimento do selo, a longo prazo, como o primeiro passo para a gestão da qualidade e SSO pelas grandes empresas do aglomerado (indústria do açúcar e álcool) e pela comunidade (empregados).

Por fim, pode-se dizer que a proposta apresentada neste artigo representa uma grande contribuição para as ações conjuntas e iniciativas de colaboração em aglomerados, contribuindo para a redução das dificuldades enfrentadas por pequenas empresas no gerenciamento e implementação de sistemas de gestão.

\section{Referências}

AGGELOGIANNOPOULOS, D.; DROSINOS, E.; ATHANASOPOULOS, P. Implementation of a quality management system (QMS) according to the ISO 9000 family in a greek small-sized winery: A case study. Food Control, v. 18, p. 1077-1085, 2007. http://dx.doi. org/10.1016/j.foodcont.2006.07.010

AMATO-NETO, J. Gestão de sistemas locais de produção e inovação (clusters/APLs): um modelo de referência. São Paulo: Atlas, 2009.

BITITCI, U. et al. Creating and managing value in collaborative networks. International Journal of Physical Distribution and Logistics Management, v. 34, n. 3-4, p. 251-268, 2004. http://dx.doi.org/10.1108/09600030410533574

BOTTANI, E.; MONICA, L.; VIGNALI, G. Safety Management System: Performance Differences Between Adopters and Non-adopters. Safety Science, v. 47, p. 155-162, 2009. http://dx.doi.org/10.1016/j. ssci.2008.05.001

BRISCOE, J. A.; FAWCETT, S. E.; TODD, R. H. The implementation and impact of ISO900 among small manufacturing enterprises. Journal of Small Business Management, v. 43, n. 3, p. 309-330, 2005. http://dx.doi. org/10.1111/j.1540-627X.2005.00139.x

CAPÓ-VICEDO, J.; EXPÓSITO-LANGA, M.; MOLINAMORALES, F. Improving SME competitiveness reinforcing interorganisational networks in industrial clusters. International Entrepreneurship and Management Journal, v. 4, p. 147-169, 2008. http:// dx.doi.org/10.1007/s11365-007-0059-7

CELIK, M. Designing of integrated quality and safety management system (IQSMS) for shipping operations. Safety Science, v. 47, p. 569-577, 2009. http://dx.doi. org/10.1016/j.ssci.2008.07.002

CENTRO NACIONAL DAS INDÚSTRIAS DO SETOR SUCROENERGÉTICO E BIOCOMBUSTÍVEIS. Serviços aos associados. Disponível em: <http:// www.ceisebr.com/site/index.php/conteudo/listar/8/ servicos-aos-associados>. Acesso em: 08 jun. 2012.

COUGHLAN, P.; COUGHLAN, D. Action research for operations management. International Journal of Operations \& Production Management, v. 22, n. 2, p. 220-240, 2002. http://dx.doi. org/10.1108/01443570210417515

GOTZAMANI, K. D. et al. The contribution to excellence of ISO 9001: the case of certified organisations in Cyprus. The TQM Magazine, v. 19, n. 5, p. 388-402, 2007. http://dx.doi.org/10.1108/09544780710817838

INSTITUTO BRASILEIRO DE GEOGRAFIA E ESTATÍSTICA - IBGE. Diretório de Negócios. Rio de Janeiro: IBGE, 2009.

INTERNATIONAL ORGANIZATION FOR STANDARDIZATION - ISO. The ISO Survey of certifications 2007. Switzerland: ISO, 2008a. ISO, 2008-11/600.

INTERNATIONAL ORGANIZATION FOR STANDARDIZATION - ISO. ISO9001: Sistema de Gestão da Qualidade - Requisitos. Switzerland: ISO, 2008b.

JONKER, J.; KARAPETROVIC, S. System thinking for the integration of management systems. Business process management journal, v. 10, n. 6, p. 608-615, 2004. http://dx.doi.org/10.1108/14637150410567839

JORGENSEN, T. H.; REMMEN, A.; MELLADO, M. D. Integrated management systems - three different 
levels of integration. Journal of cleaner production, v. 14, p. 713-722, 2006. http://dx.doi.org/10.1016/j. jclepro.2005.04.005

KARAEV, A.; KOH, S.; SZAMOSI, L. The cluster approach and SME competitiveness: a review, Journal of Manufacturing Technology Management, v. 18, n. 7 , p. 818-835, 2007. http://dx.doi. org/10.1108/17410380710817273

KOC, T. The impact of ISO9000 quality management systems on manufacturing. Journal of Materials Processing Technology, v. 186, p. 207-213, 2007. http://dx.doi.org/10.1016/j.jmatprotec.2006.12.034

KRUGMAN, P. What's new about the new economic geography? Oxford Review of Economic Policy, v. 14, n. 2, 1998. http://dx.doi.org/10.1093/oxrep/14.2.7

LABODOVA, A. Implementing integrated management systems using risk analysis based approach. Journal of cleaner production, v. 12, p. 571-580, 2004. http:// dx.doi.org/10.1016/j.jclepro.2003.08.008

MYTELKA, L.; FARINELLI, F. Local clusters, innovation systems and sustained competitiveness. Netherlands: United Nations University, 2000. Discussion paper.

MUÑIZ, B. F.; PÉON, J. M. M.; ORDÁZ, C. J. V. Relation Between Occupational Safety and Firm Performance. Safety Science, v. 47, p. 980-991, 2009. http://dx.doi. org/10.1016/j.ssci.2008.10.022

MUÑIZ, B. F.; PÉON, J. M. M.; ORDÁZ, C. J. V. Occupational risk management under the OHSAS 18001 standard: analysis of perceptions and attitudes of certified firms. Journal of Cleaner Production, v. 24, p. 36-47, 2012. http://dx.doi.org/10.1016/j. jclepro.2011.11.008

OCCUPATIONAL HEALTH AND SAFETY ASSESSMENT SERIES - OHSAS. OHSAS 18001: Sistema de Gestão de Segurança e Saúde Ocupacional - requisitos. OHSAS, 2007.

PRAJOGO, D. I. The roles of firm's motives in affecting the outcomes of ISO 9000 adoption. International Journal of Operations \& Production Management, v. 31, n. 1, p. 78-100, 2011. http://dx.doi. org/10.1108/01443571111098753

PHENG, L. S.; PONG, C. Y. Integrating ISO9001 and OHSAS 18001 for construction. Journal of construction engineering and management, v. 129, n. 3, p. 338-347, 2003. http://dx.doi.org/10.1061/ (ASCE)0733-9364(2003)129:3(338)

PORTER, M. Clusters and the new economics of competition, Harvard Business Review, p. 77-90, 1998.

PUGA, F. Alternatives of support to SMEs in Brazilian clusters. BNDES, 2003. Technical report. Disponível em: <http://www.bndes.gov.br/SiteBNDES/export/sites/ default/bndes_pt/Galerias/Arquivos/conhecimento/td/ td-99.pdf>. Acesso em: ago. 2010.

SCHMITZ, H. Collective efficiency and increasing returns. Cambridge Journal of Economics, v. 24, n. 4, p. 465-483, 1999. http://dx.doi.org/10.1093/cje/23.4.465

SCHMITZ, H.; NADVI, K. Clustering and industrialization: introduction. World Development, v. 27, n. 9, p. 1503-14, 1999. http://dx.doi.org/10.1016/ S0305-750X(99)00072-8

SIMON, A.; KARAPETROVIC, S.; CASADESUS, M. Evolution of Integrated Management Systems in Spanish firms. Journal of Cleaner Production, v. 23, p. 8-19, 2012. http://dx.doi.org/10.1016/j. jclepro.2011.10.025

SINGH, P.; FENG, M.; SMITH, A. ISO9000 series of standards: comparison of manufacturing and service organizations. International journal of quality and reliability management, v. 23, n. 2, p. 123-142, 2006. http://dx.doi.org/10.1108/02656710610640916

SINGH, P. J. Empirical Assessment of ISO9000 related management practices and performance relationships. International Journal of Production Economics, v. 113, p. 40-59, 2008. http://dx.doi.org/10.1016/j. ijpe.2007.02.047

SÖLVELL, Ö.; LINDQUIST, G.; KETELS, C. The Cluster Initiative. Stockholm: Greenbook, Bromma tryck AB, 2003.

TAMBUNAN, T. Promoting small and medium enterprises with a clustering approach: a policy experience from Indonesia. Journal of Small Business Management, v. 43, n. 2, p. 138-154, 2005. http://dx.doi. org/10.1111/j.1540-627X.2005.00130.x

TRIPP, D. Pesquisa-ação: uma introdução metodológica. Educação e Pesquisa, v. 31, p. 443-466, 2005.

UNITED NATIONS INDUSTRIAL DEVELOPMENT ORGANIZATION - UNIDO. Development of clusters and networks of SMEs. Vienna: UNIDO, 2001.

WHETTEN, D. A. What Constitutes a Theoretical Contribution?, Academy of Management Review, v. 14 , n. 4, p. 490-495, 1989.

WILKINSON, G.; DALE, B. Integrated management systems - an examination of the concept and theory. The TQM Magazine, v. 11, n. 2, p. 95-104, 1999. http:// dx.doi.org/10.1108/09544789910257280

WILKINSON, G.; DALE, B. G. Integrated management systems: a model based on a total quality approach. Managing service in quality, v. 11, n. 5, p. 318-330, 2001. http://dx.doi.org/10.1108/09604520110404040

WILKINSON, G.; DALE, B. G. An examination of the ISO 9001:2000 standard and its influence on the integration of management systems. Production Planning \& Control: The Management of Operations, v. 13, n. 3, p. 284-297, 2010.

WOLFE, D.; NELLES, J. The role of local institutions and local actors in cluster policies. In: KARLSSON, C. (Ed.). Handbook of Research on Clusters: Theories, Policies and Case Studies. Cheltenham: Edward, 2008.

YEUNG, G.; MOK, V. What are the impacts of implementing ISOs on the competitiveness of manufacturing industry in China? Journal of World Business, v. 40, p. 139-157, 2005. http://dx.doi.org/10.1016/j. jwb.2005.02.007

ZENG, S. X.; SHI, J. J.; LOU, G. X. A synergetic model for implementing an integrated management system - an empirical study in China. Journal of Cleaner Production, v. 15, p. 1760-1767, 2007. http://dx.doi. org/10.1016/j.jclepro.2006.03.007

ZUTSHI, A.; SOHAL, A. S. Integrated management system - The experiences of three Australian organisations. Journal of Manufacturing Technology Management, v. 16, p. 211-232, 2005. http://dx.doi. org/10.1108/17410380510576840 